Darmond and Sutherland also measured the NHfrequencies of compounds containing peptide bonds, but arrived at a conclusion different from ours ${ }^{3}$. They consider that the $3,280 \mathrm{~cm}^{-1}$ band arises from a structure different from that to which they assigned the $3,060 \mathrm{~cm} .^{-1}$ band. However, as stated above, such two bands can arise from a single structure in the case of $\mathrm{N}$-methyl acetamide, $\delta$-valerolactam and $\varepsilon$-caprolactam in solutions, and acetanilide and diketopiperazine in the solid state. The proof that each of these substances has a single molecular configuration which is associated in a single way is given by the mersurement of the Raman effect, infra-red absorption or dipole moment (N.methyl acetamide, $\delta$-valerolactam and $\varepsilon$-caprolactam $)^{5}$, and by $\mathrm{X}$-ray diffraction experiments (acetanilide ${ }^{B}$ and diketopiperazine ${ }^{7}$ ). For the dimer of carboxylic acids, it is also known that more than one $\mathrm{O}-\mathrm{H}$ vibration arises from a single structure ${ }^{8}$. Therefore, the appearance of more than one NH-stretching frequency cannot be used as a proof of the existence of more than one type of hydrogen bond, and the objection of Darmond and Sutherland to the structure of $\alpha$-keratin proposed by us $^{1}$ and independently by Ambrose et al. ${ }^{9}$ is not supported by our infra-red measurements.

San-ICHiro Mizushima

TakeHIKo SHIMaNOUCHI

Masamichi TsuboI

Chemical Laboratory, Faculty of Science,

Tokyo University, Bunkyoku, Tokyo. March 11.

1 Shimanouchi, T, and Mizushima, S., Kagaku, 17, 24 (1947); Bull. Chem. Soc. Japan, 21, 1 (1948). 'See also Chem. Abst., 43, 8843 (1949).

'Mizushima, S., Shimanouchi, T., Tsuboi, MI., Sugita, T., and Kato, E., Nature, 164, 918 (1949)

Darmon, S. E., and Sutherland, G. B. B. M., Nature, 184, 440 (1949) J. Amer. Chem. Soc., 69, 2074 (1949).

- Buswell A. M. Krebs, K. F., and Rodebush, W. H., J. Phys. Chem. 44, 1126 (1940). Klotz, I. M. Griswold, P., and Gruen, D. M. J. Amer. Chem. Soc., v1, 1615 (1949).

${ }^{5}$ Mizushima, S., Shimanouchi, T., Nagakura, S., Kuratani, K., Tsuboi M:, Baba, H., and Fujioka, O., J. Amer. Chem. Soc. (accepted for publication).

- Brown, C. J., and Corbridge, D. E., Nature, 162, 72 (1948).

${ }^{7}$ Corey, R. B., J. Amer. Chem. Soc., 60, 1598 (1938).

${ }^{8}$ Buswell, A. M., Rodebush, W. H., and Roy, M. F., J. Amer. Chem. Soc., 60, 2239 (1938)

Ambrose, E. J., and Hanby, W. E., Nature, 163, 483 (1949). Ambrose,

E. J., Elliot, A., and Temple, R. S., ibid., 163, 859 (1949).

\section{Locus of the Gene 'Fidget' in the House Mouse}

IN an attempt to place 'fidget' (symbol $f i$ ), described by Grüneberg', on the chromosome map of the house mouse, Mus musculus, a multiple test-cross has been made recently in this Department.

There is now adequate evidence that the locus of this gene is linked with that of Danforth's 'short tail' (symbol $S d$ ). Coupling back-cross data give a recombination value of about 25 per cent, the $\chi^{2}$ on independent segregation being more than 50 for one degree of freedom. Owing to the poor viability of the genotype $S d+f i f$, this member of the cross-over class is slightly deficient, and the recombination value may, in fact, be somewhat higher. Due to this cause also, there has been some delay in making up repulsion back-crosses. These, however, will shortly be available. Full data on the linkage so far indicated will be given as soon as balanced coupling and repulsion data have been produced.

The linkage of $S d$ and $f i$ extends the mapped portion of chromosome V. Carter and Grüneberg ${ }^{2}$ report a loose linkage of 'fidget' and the 'agouti' locus, of which the latter is already mapped on chromosome V. Data on $S d$ and 'agouti', available in this Department, give evidence of a looser linkage, about 40 per cent recombination; this has been further corroborated by news of D. Kelton's work at Bar Harbor. The order appears, then, to be $S d-f i-A$. Work is now in progress in this Department to determine the exact linkage relations between these three loci and those already mapped on this chromosome.

Department of Genetics,

M. E. WALLACE

University of Cambridge. May 13.

${ }^{1}$ Grüneberg, H., J. Genet., 45, 22 (1943).

${ }^{2}$ Heredity (in the press).

\section{Fertilization of the Rat Egg}

The use of the phase-contrast microscope for the study of certain stages in the fertilization of rat eggs has been described ${ }^{\mathbf{1}}$. It was pointed out that pressing the eggs beneath a coverslip greatly improved the visibility of the internal structure. More recently, it has been found that, if the Fallopian tubes are dissected under liquid paraffin and the eggs transferred to a slide with some of the fluid which surrounds them while in the Follopian tube, they would survive for several hours even when pressed beneath a coverslip. During this period the changes involved in fertilization proceeded in an apparently normal manner, and could readily be observed and photographed.

The time of survival differed with individual eggs and also with the degree of pressure to which they were subjected, but was usually not less than six to eight hours or more than twelve to sixteen hours. Within limits, the more the eggs are compressed the greater is visibility improved; but survival, and the occurrence of certain of the changes, are apt to be interfered with if the vertical thickness of the vitellus is reduced to less than about $15 \%$. The optimal thickness seems to be about $20 \mu$.

Under the conditions described, it has been possible to observe in detail, and to photograph, the occurrence in vitro of the following complete series of changes : (a) the detachment of the sperm head and the conversion of its substance, with the exception of the apical cap or acrosome, into the male pronucleus; the acrosome remains unchanged and is recognizable in eggs recovered at later stages; (b) the changes in the second maturation spindle consequent upon sperm penetration as far as the formation of the female pronucleus ; $(c)$ part of the growing phase of the pronuclei; (d) the sequence of events from the conjugation of the pronuclei to the formation of the two-cell nuclei ; as yet, however, the actual division of the cytoplasm to form a two-cell egg has not been found to occur under the conditions employed.

These observations and photographic records, together with data on the time relations of the stages of fertilization in vivo as well as in vitro, are being prepared for publication.

Commonwealth Scientific and

Industrial Research Organisation,

Division of Animal Health and Production,

McMaster Animal Health Laboratory,

Parramatta Road,

Glebe, N.S.W.

April 27.

${ }^{1}$ Austin and Smiles, J. Micr. Soc., 68, 13 (1948). 